\title{
SOLID PARTICLE EROSION IN THE SUDDEN CONTRACTION OF RAW WATER PIPELINE
}

\author{
Karima E. AMORI, Zaid Al-SALMANY \\ University of Baghdad, College of Engineering, Mechanical Engineering Department, Baghdad, Iraq \\ Karema.i@coeng.uobaghdad.edu.iq
}

\begin{abstract}
The steady 3-D raw water turbulent flow is numerically investigated. This flow is formed of solid silica sand (quartz) carried by water in stainless steel pipe. The flow in a straight pipe and flow in a pipe with a sudden contraction are analyzed using a two-way coupled Eulerian-Lagrangian approach. Erosion rate is estimated by Oka erosion model combined with the constant coefficient of restitution. The effect of solid particles mass flow rate, inlet velocity, particle diameter, internal pipe diameter, orientation, contraction coefficient, and wall pipe contraction angle on erosion rate are examined. The predicted erosion is distributed homogenously for straight pipe, while the step wall area of the contraction is the most eroded part. The erosion rate increases with the increase of solid particles diameter, flow rate, inlet velocity, and decreasing pipe diameter. Iit is found that the erosion is limited till the particle diameter reaches $500 \mu \mathrm{m}$ then it starts to increase. The erosion rate increases with decreasing contraction coefficient and step wall angle. When the step wall angle decreased to 300 , the erosion rate is reduced by 30 times that for 900 . So, decreasing step wall angle can be considered as a geometrical solution to reduce erosion rate.
\end{abstract}

Keywords: (erosion, solid particle, CFD, model calculation, pipe contraction)

\section{INTRODUCTION}

Erosion due to solid particle impact is the most serious problem that occurs in piping fittings in different industrial applications such as: oil and gas production, water filtration stations, turbines, pumps etc. The erosion causes serious problems such as: leakage, vibration, energy losses, a complete failure of the turbomachine and economic loss. Studying solid particle erosion in multiphase flow still remains a challenging area for researches, since predicting the motion of particles before and after impaction and knowing impaction properties in turbulent flow as well as the effect of forces acting on particle by the fluid itself are not an easy task.

Many previously studies related to the erosion in pipe and pipes fittings due to fluid-solid flow are found. Al-Baghdadi et al. [2] developed a 3-D Computational Fluid Dynamics (CFD) model to describe the turbulent transport of sand particles and crude oil through elbows to estimate erosion rate. AlKhayat et al. [3] studied the erosion due to 3-D flow of crude oil in elbow using CFD. The friction forces between crude oil or sand particles and pipe wall, fluid viscosity, temperature, density and mass flow rate has been studied in the model and well agreed with previously published results. Ataiwi et al. [5] and Yousif et al. [43] studied experimentally the effect of particle size, impingement angle and the effect of using mixed grain size of particles rather than using only one size on erosion rate. Clark [6] illustrated that the solid particle erosion depends on particle properties, metallic properties, geometry, type of flow and flow pattern. The erosion mechanism in both ductile and brittle materials was extensively studied by Finnie [8,9], Jordan [15], Hutchings and Winter [11], Leavy [18], Mansouri [20] and others. For ductile material, the erosion occurs by scraping mechanism or plastic deformation mechanism. The erosion in brittle material is widely understood, which occurs by formation and propagation of crakes by chipping mechanism or cracking mechanism. The influence of wall roughness on erosion rate in gas-solid turbulent annular pipe flow was numerically studied by Jafri et al. [12]. The effect of impingement angle, velocity, particle size and concentration on erosion rate in slurry flow was experimentally investigated by Jha et al. [13] and Patil et al. [31]. An experimental and CFD erosion modelling of large radius pipe elbows with solid-liquid flow is presented by Johar et al. [14]. Kang et al. [16] presented an integral model for predicting sand erosion in elbow for gas-liquid multiphase flow, the effect of flow pattern (bubble flow, slug flow, churn flow and annular flow) on erosion rate has been examined. The erosion model also validated with 108 experiments and reported a good matching.

(C) 2022 by the Authors. Licensee Polish Society of Technical Diagnostics (Warsow. Poland). This article is an open access article distributed under the terms and conditions of the Creative Commons Attribution (CC BY) license http://creativecommons.org/licenses/by/4.0/). 
Other researches are studied the solid particle erosion in other complex geometries. Kosinska et al. [17] analyzed theoretically the erosion due to the simulated fluid flow laden with nano and micro sized particles in pipe elbow, the results are validated with experiments and they were coincided. Mazumdar et al. [21] measured the particle impact velocity that cause erosion wear in solid-liquid flow in elbow numerically and experimentally. The numerical study is presented by using discrete phase model (DPM) with erosion/accretion model in the commercial CFD Fluent software. The experimental study is presented using Particle Image Velocimetry (PIV) technique. The numerical and experimental studies showed a good agreement. The effect of elbow radius on pressure drop in multiphase flow was also numerically investigated [22]. Mazumder [23] simulated the effect of fluid-solid flow velocity, particle size and type of fluid on the location and magnitude of maximum erosion in $U$ bend. Meng and Ludema [24] presented erosion models previously developed and the parameters that affect the erosion rate. They found that there are 28 erosion models related with solid particle erosion and 33 parameters affect the erosion. Parsi et al. [30] investigated experimentally the effect of flow pattern and flow orientation on erosion caused by sand particles in elbows with gas-liquid-solid multiphase flow condition. Ultrasonic Technique (UT) is used to measure erosion rate and the technique of Wire Mesh Sensor (WMS) is used to study flow pattern and their effects on erosion. Peng and Cao [32] performed a numerical simulation to study solid particle erosion in a pipe bend for solid-liquid flow. The effect of Stokes number, bend orientation and flow direction on the maximum erosion rate was also studied. Peng et al. [33] studied numerically and experimentally the erosion by sand entrained in slug flow in a horizontal pipe bend. The experimental study applied by designing a flow loop with a detachable test pipe bend and the numerical study applied by Volume Of Fluid model (VOF) and Discrete Phase Model (DPM) model in the commercial CFD Fluent code. Raghavendra et al. [35] presented a CFD simulation of erosion wear by sand-water flow in choke valves. The net eroded surface was measured by using modern technique which is Coordinate Measurement Machine (CMM). Shamshirband et al. [38] presented a performance investigation of micro and nano sized particles caused erosion in elbow using adaptive Neuro-Fuzzy Interface System (ANFIS) model. Vieira et al. [41] measured elbow solid particle erosion in multiphase annular flow by using an electrical resistance probe. Other parameters are also examined such as: particle size, fluid viscosity, liquid flow rate, orientation and location of probe. Zhang et al. [44] studied the erosion caused by solid-gas flow in a model of break valve.

It is clear that the erosion of simple piping geometries such as straight pipe and pipe bend is studied in the most of the previous studies. While, a rare erosion investigation in the more complex piping fittings is available. The objectives of this work are: first, to conduct a parametric study of the solid particle erosion using CFD technique on flow through more complex piping geometries such as: pipe with sudden contraction. Second, study the effects of some parameters that related to sand-water two phase turbulent flow with erosion. Third, to propose a geometrical solution to reduce erosion rate.

\section{MATHEMATICAL MODEL}

In this work, three mathematical models namely: flow modelling, particle tracking and erosion prediction are utilized to study solid particle erosion problem.

\subsection{Flow modelling}

The Eulerian-Lagrangian approach is used to model the solid-liquid flow by solving Reynolds Averaged Navier-Stock's equations (RANS) in Eulerian scheme. While, the particles are treated as discrete phase. The trajectories of solid particles are computed by solving the equation of motion of particles through using Discrete Phase Model (DPM) in Lagrangian scheme [1]. The Eulerian-Lagrangian approach is only applicable when the volume fraction of solid particles is low comparing with that of fluid phase. Because, with increasing particles, the computational time increased and simulation quality reduced and the particles trajectories are required to solve for each parcel [39]. The volume fraction of solid particles should not exceed $10 \%-12 \%$ to be able to use DPM model and the particles are diluted in the fluid phase [4]. A Newtonian incompressible three-dimensional (3-D) fluid flow with constant thermophysical properties are considered in this work. The governing differential equations for continuity and momentum are: [4, 42]

$$
\begin{aligned}
& \frac{\partial \rho}{\partial t}+\vec{\nabla} \cdot(\rho \vec{v})=0 \\
& \frac{\partial}{\partial t}(\rho \vec{v})+\vec{\nabla} \cdot(\rho \vec{v} \vec{v})=-\vec{\nabla} p+ \\
& \vec{\nabla} \cdot\left[\mu\left(\left(\nabla \vec{v}+\nabla \vec{v}_{t}\right)\right)\right]+\rho \vec{g}+\vec{S}_{M}
\end{aligned}
$$

where:

$\vec{v}$ is the fluid velocity vector in the cylindrical coordinate system $(\mathrm{m} / \mathrm{s})$, which is defined:

$$
\vec{v}=v_{r} \dot{r}+v_{\theta} \dot{\theta}+v_{z} \dot{z}
$$

where:

$\dot{r}, \dot{\theta}$ and $\dot{z}$ are unit vectors in the $r, \theta$, and $z$ directions respectively.

$v_{r}, v_{\theta}$, and $v_{z}$ are the velocity components $(\mathrm{m} / \mathrm{s})$ in the $r, \theta$ and $z$ directions respectively.

$\vec{\nabla}$ is the dell operator vector (gradient operator) which is defined as:

$$
\vec{\nabla}=\frac{\partial}{\partial r} \dot{r}+\frac{\partial}{\partial \theta} \dot{\theta}+\frac{\partial}{\partial z} \dot{z}
$$

$\rho$ is the fluid density $\left(\mathrm{kg} / \mathrm{m}^{3}\right)$.

$p$ is the pressure $(\mathrm{Pa})$.

$\vec{g}$ is the gravitational acceleration $\left(\mathrm{m} / \mathrm{s}^{2}\right)$.

$\mu$ is the dynamic viscosity of the fluid (kg/m.s). 
$v_{t}$ is the fluctuated velocity due to turbulence $(\mathrm{m} / \mathrm{s})$. $S_{m}$ is the momentum transfer between fluid phase and solid particle phase $\left(\mathrm{kg} / \mathrm{m}^{2} \cdot \mathrm{s}^{2}\right)$.

\subsubsection{Turbulence model}

The standard $\mathrm{k}-\varepsilon$ turbulence model is adopted to resolve flow turbulence. The model is chosen because of its' computational efficiency and its' simplicity [37]. The flow is assumed as a fully turbulent and the effects of molecular viscosity are neglected [4]. The standard $\mathrm{k}-\varepsilon$ model is semiempirical model which consists of the turbulent kinetic energy $(\mathrm{k})$ equation and the dissipation rate of turbulent kinetic energy $(\varepsilon)$ equation such that:

$$
\begin{gathered}
\frac{\partial}{\partial t}(\rho k)+\nabla \cdot(\rho \vec{v} k)=\nabla \cdot\left[\left(\mu+\frac{\mu_{t}}{\sigma_{k}}\right) \nabla k\right]+ \\
G_{K}-\rho \varepsilon+S_{K} \\
\frac{\partial}{\partial t}(\rho \varepsilon)+\nabla \cdot(\rho \vec{v} \varepsilon)=\nabla \cdot\left[\left(\mu+\frac{\mu_{t}}{\sigma_{\varepsilon}}\right) \nabla \varepsilon\right]+ \\
\frac{\varepsilon}{k}\left(C_{\varepsilon 1} G_{K}-\rho \varepsilon C_{\varepsilon 2}\right)+S_{\varepsilon}
\end{gathered}
$$

where:

$k$ is the turbulence kinetic energy $\left(\mathrm{m}^{2} / \mathrm{s}^{2}\right)$.

$\varepsilon$ is the dissipation in the turbulent kinetic energy $\left(\mathrm{m}^{2} / \mathrm{s}^{3}\right)$.

$\mu_{t}$ is the turbulent (or eddy) viscosity ( $\mathrm{kg} / \mathrm{m} . \mathrm{s}$ ), which is obtained as:

$$
\mu_{t}=\rho C_{\mu} \frac{k^{2}}{\varepsilon}
$$

$\sigma_{k}$ is the turbulent Prandtl number for $\mathrm{k}$ which equal to (1.0).

$\sigma_{\varepsilon}$ is the turbulent Prandtl number for $\varepsilon$ which equal to $(1.3)$.

$G_{K}$ is the generation of turbulent kinetic energy due to the mean velocity gradient $\left(\mathrm{kg} / \mathrm{m} \cdot \mathrm{s}^{3}\right)$. It is obtained as: [30]

$$
G_{K}=\mu_{t} \nabla \vec{v} \cdot\left(\nabla \vec{v}+\nabla \vec{v}_{t}\right)-\frac{2}{3} \nabla \cdot \vec{v}\left(3 \mu_{t} \nabla \cdot \vec{v}+\rho k\right)
$$

$C_{\varepsilon 1}, C_{\varepsilon 2}$ and $C_{\mu}$ are constants and equal to $1.44,1.92$ and 0.09 respectively.

$S_{K}$ is the source term for turbulent kinetic energy $\left(\mathrm{kg} / \mathrm{m} \cdot \mathrm{s}^{3}\right)$.

$S_{\varepsilon}$ is the source term for the dissipation rate of turbulent kinetic energy $\left(\mathrm{kg} / \mathrm{m} . \mathrm{s}^{4}\right)$.

\subsection{Particle tracking}

The Lagrangian scheme is adopted to track the solid particles trajectories in the flow by solving particle's equation of motion (Newton's equation of motion). The software integrates the force balance for particle to find the particle trajectory and this force balance equals the particle inertia with forces acting on the particle and this is called "Discrete Phase Model" (DPM) [1]. Particle tracking is based on assuming constant thermophysical properties for solid particles. The particles injected with the same fluid velocity at pipe inlet. The particle is carried out by the fluid and no particle-particle interaction occurs. The particle has a semi-round shape and it would not deform or break during collision. The particle's equation of motion is: [42]

$m \frac{d \vec{v}_{p}}{d t}=\sum F=\vec{F}_{D}+\vec{F}_{P}+\vec{F}_{V M}+\vec{F}_{G}+\vec{F}_{B}$ where:

$\vec{v}_{p}$ is the particle velocity vector in the cylindrical coordinate system $(\mathrm{m} / \mathrm{s})$ which is defined:

$$
\vec{v}_{p}=v_{p r} \dot{r}+v_{p \theta} \dot{\theta}+v_{p z} \dot{z}
$$

in which, $v_{p r}, v_{p \theta}$ and $v_{p \mathrm{z}}$ are the particle velocity components in the $r, \theta$ and $z$ directions respectively.

$m$ is particle mass $(\mathrm{kg})$.

$F_{D}$ is the drag force $(\mathrm{N})$.

$F_{P}$ is the pressure gradient force $(\mathrm{N})$.

$F_{V M}$ is the virtual mass force $(\mathrm{N})$.

$F_{G}$ is the gradient gravity force $(\mathrm{N})$.

$F_{B}$ is the buoyancy force $(\mathrm{N})$.

The Magnus, Basset and Shaffman lift forces are neglected because they are too small comparing with other acting forces when the carrier fluid is water [4]. The drag force is defined as:

$$
\vec{F}_{D}=C_{D} \rho \frac{\pi d_{p}^{2}}{8}\left|\vec{v}-\vec{v}_{p}\right|\left(\vec{v}-\vec{v}_{p}\right)
$$

where:

$d_{p}$ is the particle diameter $(\mathrm{m})$.

$C_{D}$ is the drag coefficient.

Several drag laws are available in EulerianLagrangian model. In this study, the spherical drag law is used:

$$
C_{D}=a_{1}+\frac{a_{2}}{R e_{p}}+\frac{a_{3}}{R e_{p}^{2}}
$$

where:

$R e_{p}$ is the particle relative Reynolds number.

The constants $a_{1}, a_{2}$ and $a_{3}$ are obtained according to the particle relative Reynolds number $\left(R e_{p}\right)$ as given in Table (1) [25]:

Table 1. Drag coefficients [34]

\begin{tabular}{cccc}
\hline Reynolds range & $a_{1}$ & $a_{2}$ & $a_{3}$ \\
\hline $\operatorname{Re}_{\mathrm{p}}<0.1$ & 0 & 24.0 & 0 \\
\hline $0.1<\mathrm{Re}_{\mathrm{p}}<1.0$ & 3.69 & 22.73 & 0.0903 \\
\hline $1.0<\mathrm{Re}_{\mathrm{p}}<10.0$ & 1.222 & 29.1667 & -3.8889 \\
\hline $10.0<\mathrm{Re}_{\mathrm{p}}<100$ & 0.6167 & 46.5 & -116.67 \\
\hline $100<\mathrm{Re}_{\mathrm{p}}<1000$ & 0.3644 & 98.33 & -2778 \\
\hline $10^{3}<\mathrm{Re}_{\mathrm{p}}<5^{*} 10^{3}$ & 0.357 & 148.62 & $-4.755 \times 10^{4}$ \\
\hline $5^{*} 10^{3}<\mathrm{Re}_{\mathrm{p}}<10^{4}$ & 0.46 & -490.546 & $5.787 \times 10^{5}$ \\
\hline $10^{4}<\mathrm{Re}_{\mathrm{p}}<5^{*} 10^{4}$ & 0.5191 & -1662.5 & $5.4167 \times 10^{6}$ \\
\hline
\end{tabular}

$$
R e_{p}=\rho \frac{\left|\vec{v}-\vec{v}_{p}\right|}{\mu} d_{p}
$$

The buoyancy and gravity forces are combined together such that:

$$
\vec{F}_{B}=\left(\rho_{P}-\rho\right) \vec{g} \frac{\pi d_{p}^{3}}{6}
$$

In which $\rho_{P}$ is the density of solid particles $\left(\mathrm{kg} / \mathrm{m}^{3}\right)$.

The virtual mass force is defined as:

$$
\vec{F}_{V M}=\frac{\pi d_{p}^{3}}{12} \rho \frac{d}{d t}\left(\vec{v}-\vec{v}_{p}\right)
$$

The pressure gradient force is expressed as:

$$
\vec{F}_{P}=\rho \frac{\pi d_{p}^{3}}{6} \vec{v}_{p} \nabla \vec{v}
$$

\subsubsection{Coupling between two phases}

The coupling (interaction) between solid phase and the fluid phase is expressed by the momentum exchanged between the two phases, that is called 
"coupling". In this study, the two-way coupling is adopted i.e the carrier fluid influences the solid particles via drag and turbulence, and the solid particles turn influence via turbulence and reduction in momentum. The interaction between phases is done through the source terms: $\left(S_{M}\right)$ in equation (2), $\left(S_{k}\right)$ in equation (5) and $\left(S_{\varepsilon}\right)$ in equation (6), in which these effects are considered [32].

\subsubsection{Momentum coupling}

The momentum exchanged between the two phases is computed by examine the momentum changing in particle for each control volume. The momentum changing is computed as: [4,32]

$$
S_{M}=\sum\left(F_{D}+F_{P}+F_{V M}+F_{B}\right) m_{p} \Delta t
$$

Where, $m_{p}$ is the mass flow rate of solid particles $(\mathrm{kg} / \mathrm{s})$, and $\Delta t$ is the time step (s).

\subsubsection{Turbulence coupling}

Fluid velocity is formed of mean and random fluctuated velocity, such as:

$$
\begin{aligned}
& v_{r}=\overline{v_{r}}+\grave{v}_{r} \\
& v_{\theta}=\overline{v_{\theta}}+\grave{v_{\theta}} \\
& v_{z}=\overline{v_{z}}+v_{z}
\end{aligned}
$$

where:

$\overline{v_{r}}, \overline{v_{\theta}}$ and $\overline{v_{z}}$ are the mean fluid velocity in the $r, \theta$ and $z$ directions respectively.

$\grave{v}_{r}, \grave{v}_{\theta}$ and $\grave{v}_{z}$ are the random fluctuated velocity in the $r, \theta$ and $z$ directions respectively.

The random fluctuated velocity $\left(\grave{v}_{r}, v_{\theta}\right.$ and $\left.\grave{v}_{z}\right)$ influences the particles trajectories. In this work, the particle-eddy interaction model proposed by Gosman and Ioannides [10] is adopted. The effect of turbulence on solid particles is considered by using Discrete Random Walk (DRW) model, or (eddy life) model. In which, each eddy is characterized by the Gaussian distributed of random fluctuation velocity $\grave{v_{r}}, \grave{v_{\theta}}$ and $\grave{v}_{z}:[4,32]$

$$
\begin{aligned}
& v_{r}{ }^{\prime}=\zeta \sqrt{\overline{v_{r}^{\prime 2}}} \\
& v_{\theta}{ }^{\prime}=\zeta \sqrt{\overline{v_{\theta}^{\prime 2}}} \\
& v_{z}{ }^{\prime}=\zeta \sqrt{\overline{v_{z}^{\prime \prime}}}
\end{aligned}
$$

where:

$\zeta$ is the random number that obeys normal distribution and the right-hand side terms represent the local Root-Mean-Square (RMS) value of the velocity fluctuation.

The two-way coupling enables to consider the effects of changing turbulence quantities due to particle damping and turbulence eddies by modification the source terms $\left(S_{k}\right)$ and $\left(S_{\varepsilon}\right)$ in the standard k- $\varepsilon$ model by the formulation described in [7].

\subsubsection{Particle impact and rebound behaviour}

When solid particle collides the wall, some of its' energy will lose and the rebounded velocity after impaction will be less than the incident velocity before impaction [32]. The coefficient of restitution is defined as the ratio of the post-collision and precollision velocities which is consists of two components, one cats along the normal and the other acts along the tangential of the wall [21]. According to [36], the average coefficient of restitution for quartz sand particles collide with stainless steel material is 0.68 .

\subsection{Erosion prediction}

In this work, the Oka erosion model is adopted since it is related with the most effective parameters on erosion such as: particles' diameter, impact angle, velocities and material properties for particles and target material. The thermophysical properties for wall material are considered constant and the deformation of wall material due to solid particles collision is ignored in this model. The erosion rate according to $[3,32]$ is expressed as:

$$
\begin{aligned}
& E R=1.0 \times 10^{-9} \rho_{w} k f(\alpha)\left(H_{v}\right)^{k 1}\left(\frac{v_{p}}{v^{*}}\right)^{k 2} \\
& f(\alpha)=(\sin \alpha)^{n 1}\left[1+H_{v}(1-\sin \alpha)\right]^{n 2}
\end{aligned}
$$

where:

$\rho_{w}$ is the density of target material $\left(\mathrm{kg} / \mathrm{m}^{3}\right)$.

$H_{v}$ is Vickers hardness of target material (GPa).

$\alpha$ is the impact angle between solid particle and target material (degree).

$v^{*}$ is the reference velocity of solid particle $(\mathrm{m} / \mathrm{s})$. $d^{*}$ is the reference particle diameter $(\mu \mathrm{m})$.

$k, k 1, k 2, k 3, n 1$ and $n 2$ are constants, their values are given in Table (2).

Table 2. The values of constants parameters in Oka erosion model [28]

\begin{tabular}{cccc}
\hline$k$ & $k 1$ & $k 2$ & $k 3$ \\
\hline 65 & -0.12 & $2.3\left(H_{v}\right)^{0.038}$ & 0.19 \\
\hline$n 1$ & $n 2$ & $v^{*}(\mathrm{~m} / \mathrm{s})$ & $d^{*}(\mu \mathrm{m})$ \\
\hline $0.71\left(H_{v}\right)^{0.14}$ & $2.4\left(H_{v}\right)^{-0.94}$ & 104 & 326 \\
\hline
\end{tabular}

The stainless steel $304 \mathrm{H}(\mathrm{SS} 304 \mathrm{H})$ has been chosen to be the main material of the piping wall, since it has a high resistance of corrosion [19]. The solid particles have been chosen to be silica sand (quartz) and the carrier fluid is the water. The physical properties of SS304H, quartz sand and water are listed in Table (3).

Table 3. Physical properties for SS304H, Quartz sand and water [27, 28 and 45]

Stainless steel 304H (SS304H)

\begin{tabular}{cc}
\hline Density $\left(\mathrm{kg} / \mathrm{m}^{3}\right)$ & 7890 \\
\hline Young modules $(\mathrm{MPa})$ & $1.948 \times 10^{5}$ \\
\hline Poisson ratio & 0.27 \\
\hline Vickers hardness $(\mathrm{GPa})$ & 1.8 \\
\hline Internal diameter $(\mathrm{m})$ & 0.4064 \\
\hline \multicolumn{2}{c}{ Quartz sand } \\
\hline Density $\left(\mathrm{kg} / \mathrm{m}^{3}\right)$ & 2600 \\
\hline Young modules $(\mathrm{MPa})$ & 370 \\
\hline Poisson ratio & 0.3 \\
\hline Diameter $(\mathrm{m})$ & $4 \times 10^{-4}$ \\
\hline \multicolumn{2}{c}{ Water } \\
\hline Density $\left(\mathrm{kg} / \mathrm{m}^{3}\right)$ & 998.2 \\
\hline Dynamic viscosity (pa s) & $1.003 \times 10^{-3}$ \\
\hline
\end{tabular}




\section{COMPUTATIONAL ANALYSES}

\subsection{Physical and computational domain}

ANSYS-Fluent 2020 R2 Computational Fluid

Dynamics (CFD) software is used to simulate solid particle erosion for sand-water two-phase 3-D flow through two piping geometries namely: straight pipe and pipe with sudden contraction as presented in Fig. (1). The internal diameter for the straight pipe is $406.4 \mathrm{~mm}$ (16 inch) with $8128 \mathrm{~mm}$ length. While, the pipe with sudden contraction has internal diameters of $406.4 \mathrm{~mm}$ for the larger section and 300 $\mathrm{mm}$ for the smaller section with $4064 \mathrm{~mm}$ length for each part. The pipe wall material is $\mathrm{SS} 304 \mathrm{H}$ with the physical properties given in Table (3). The established assumptions are: Steady turbulent 3-D flow, Newtonian incompressible fluid, constant thermophysical properties, the solid particles are at the same fluid velocity at the pipe inlet, no particleparticle interaction occurs. The Magnus, Basset and Shaffman lift forces on particle are neglected. The particles have a semi-round shape and they would not deform or break during collision and the wall deformation caused by particles collision is not considered.
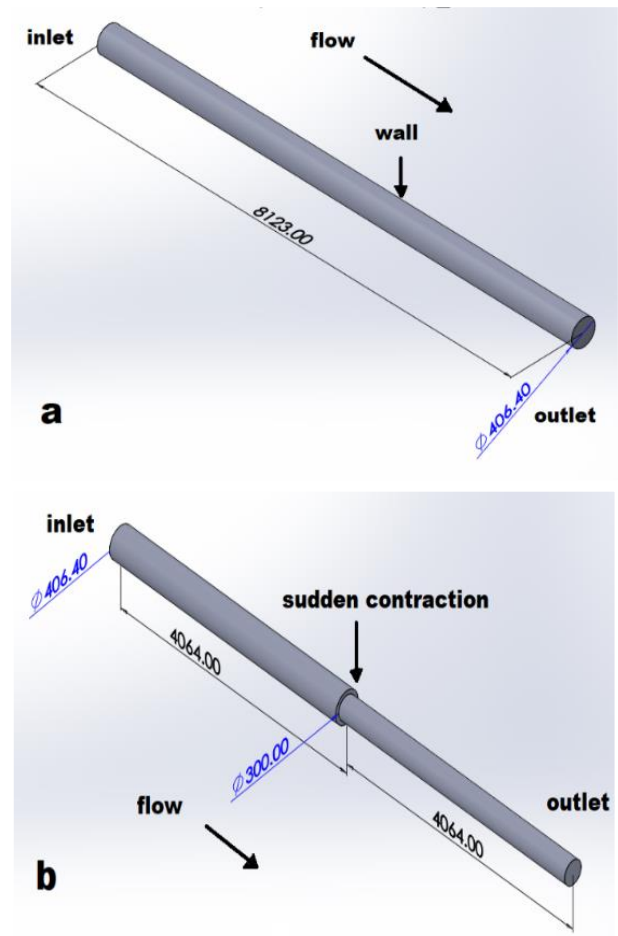

Fig. 1. (a) Straight Pipe (b) Pipe with Sudden Contraction

Table 4. Boundary conditions for continuous phase and dispersed phase

\begin{tabular}{cccc}
\hline \multicolumn{2}{c}{ Continues Phase } & \multicolumn{2}{c}{ Dispersed Phase } \\
\hline Inlet & Constant Velocity & Inlet & "Escape" \\
\hline Outlet & Constant Pressure & Outlet & "Escape" \\
\hline Wall & No-Slip Condition & Wall & "Reflect" \\
\hline
\end{tabular}

The boundary conditions for the continuous phase (water) and dispersed phase (sand particles) are listed in Table (4).

\subsection{Grid generation}

ANSYS ICEM CFD software is adopted to generate hexahedral mesh to guarantee more stability and generate fewer highly distorted elements for three dimensional piping geometries as presented in Fig. (2). Also the computational accuracy of hexahedral elements is higher than the tetrahedral one. Near wall finer grid is generated to capture the boundary layer as illustrated in the zoomed section in Fig. (2).
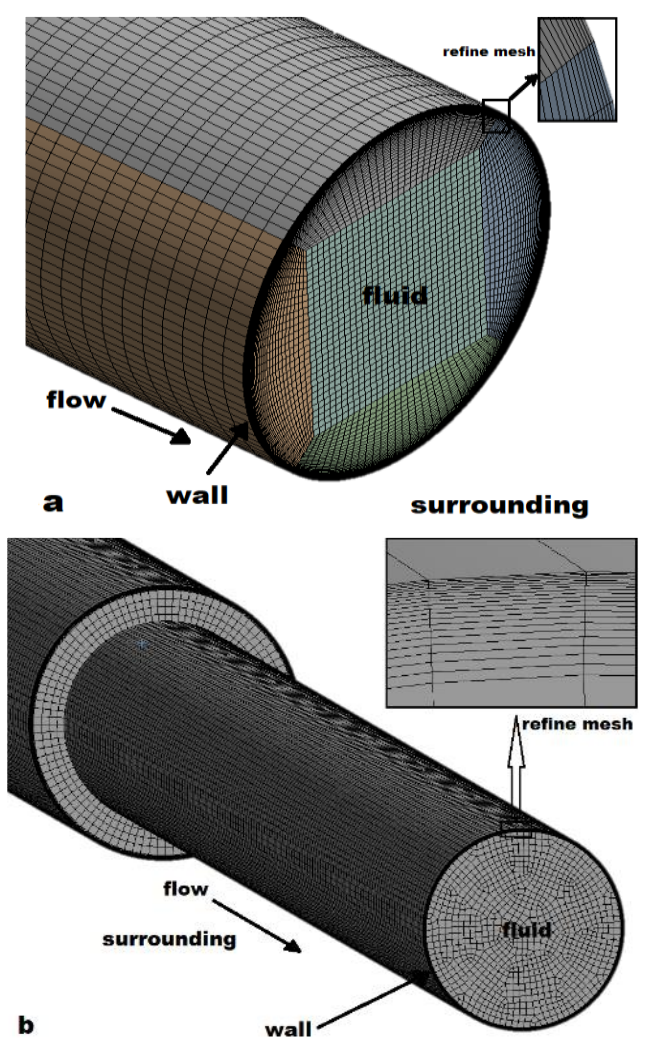

Fig. 2. The hexahedral mesh in (a) straight pipe (b) pipe with sudden contraction

Grid independency is accomplished by solving water flow (single phase) to compute water velocity at different sections in each geometry. The middle and outlet sections for straight pipe are selected. While, for the pipe with sudden contraction, the middle and outlet sections for small pipe diameter are checked. It is showed that the best mesh density for straight pipe and for pipe with sudden contraction is 717120 and 629620 hexahedral cells respectively as shown in Fig.s (3) and (4).

\subsection{Numerical scheme}

The numerical scheme settings for water-sand two-phase flow through straight pipe and pipe with sudden contraction are given in Table (5). For the convergence and stability of solution, appropriate setting values of under-relaxation factors and residual should be selected. The values of under- 
relaxation factors are given in Table (6). The maximum residual value for all parameters has been set as default to be 0.001 .

The numerical simulation of water-sand twophase flow through two piping geometries is performed according to the flow conditions given in Table (7).

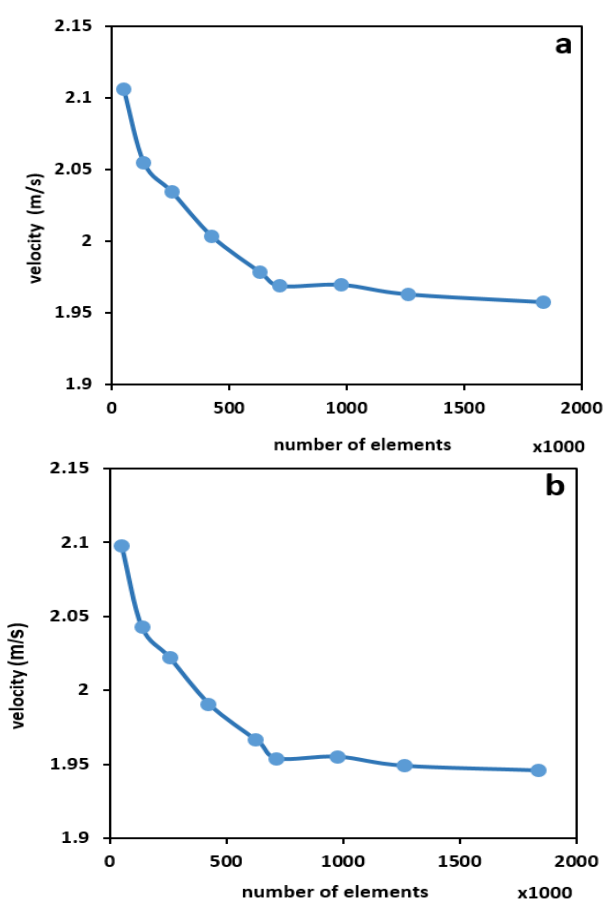

Fig. 3. Grid independency for straight pipe case at: (a) middle section (b) outlet section
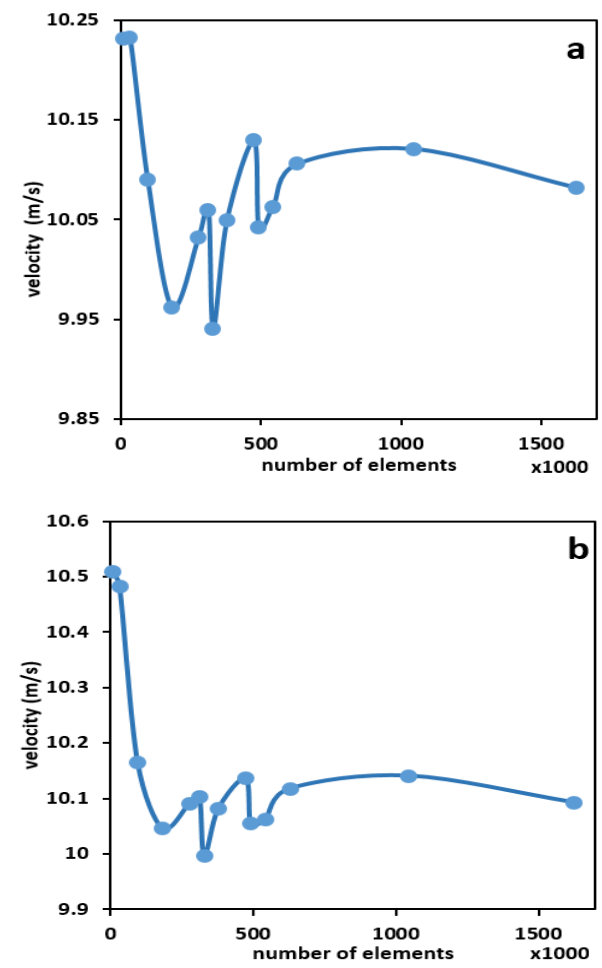

Fig. 4. Grid independency for pipe with sudden contraction case at: (a) middle section of small pipe (b) outlet section of small pipe

\subsection{Validation of the model}

The present computational results are verified with the experimental results by Postlethwaite and Nesic [34]. They measured the erosion rate for slurry flow (water-silica sand flow) through sudden contraction, groove and sudden expansion, as shown in Fig. (5). The experimental parameters and flow condition of the study are given in Table (8).

Table 5. Numerical Scheme

\begin{tabular}{|c|c|}
\hline Variable & Sittings \\
\hline Solver type & Pressure-based solver \\
\hline Pressure-velocity coupling & SIMPLIC algorithm \\
\hline $\begin{array}{l}\text { Pressure spatial } \\
\text { discretization }\end{array}$ & Second order \\
\hline $\begin{array}{c}\text { Momentum spatial } \\
\text { discretization }\end{array}$ & Second order upwind \\
\hline $\begin{array}{l}\text { Turbulent kinetic energy } \\
\text { spatial discretization }\end{array}$ & Second order upwind \\
\hline $\begin{array}{l}\text { Turbulent dissipation rate } \\
\text { spatial discretization }\end{array}$ & Second order upwind \\
\hline Turbulence model & Standard k- $\varepsilon$ model \\
\hline Near wall treatment & Scalable wall function \\
\hline Particle treatment & $\begin{array}{c}\text { Discrete Phase Model } \\
\text { (DPM) }\end{array}$ \\
\hline Particle tacking scheme & Trapezoidal \\
\hline Interaction between phases & Two-way coupling \\
\hline Erosion estimation & Oka erosion model \\
\hline
\end{tabular}

Table 6. Under-Relaxation Factors

\begin{tabular}{cc}
\hline Parameters & Value \\
\hline Pressure & 0.3 \\
\hline Density & 1 \\
\hline Body forces & 1 \\
\hline Momentum & 0.7 \\
\hline Turbulent kinetic energy & 0.8 \\
\hline Turbulent dissipation rate & 0.8 \\
\hline Discrete phase sources & 1 \\
\hline
\end{tabular}

Table 7. Flow conditions of the numerical simulation

\begin{tabular}{cc}
\hline Parameter & Values \\
\hline Carrier fluid & water \\
\hline Solid particles & Quartz sand \\
\hline Piping wall material & Stainless steel 304H \\
\hline Mass flow rate for & $(1,5,10,50$ and 100$) \times$ \\
particles $(\mathrm{kg} / \mathrm{s})$ & $10^{-3}$ \\
\hline Inlet velocity $(\mathrm{m} . \mathrm{s})$ & $6,7,8,9$ and 10 \\
\hline Particle size $(\mu \mathrm{m})$ & $400,450,500,550$ and \\
& 600 \\
\hline Pipe diameter $(\mathrm{mm})$ & $406.4,350,300,250$ and \\
& 203.2 \\
\hline Orientation & Horizontal and vertical \\
\hline $\begin{array}{c}\text { Contraction coefficient in } \\
\text { pipe with sudden } \\
\text { contraction }\end{array}$ & $0.741,0.544,0.378,0.25$ \\
and 0.136 \\
\hline $\begin{array}{c}\text { Step wall angle of the } \\
\text { contraction }\end{array}$ & $90^{\circ}, 75^{\circ}, 60^{\circ}, 45^{\circ}$ and $30^{\circ}$ \\
\hline
\end{tabular}


To validate the erosion in straight pipe and in pipe with sudden contraction, section 1 and section 2 in Fig. (5) is simulated with the flow conditions given in Table (8) respectively. The validation of straight pipe case (section 1) showed a good agreement with experiments with a percentage deviation of $7.6 \%$. Where, the maximum erosion from experiments is $(7.57 \mathrm{~mm} /$ year $)$ and from numerical simulation is $(7 \mathrm{~mm} /$ year $)$ as shown in Fig. (6). Also, the validation of pipe with sudden contraction (section 2) showed an acceptable agreement with experiments with $11 \%$ deviation. In which, the maximum erosion from experiments is (137 $\mathrm{mm} /$ year) and from numerical simulation is (121.9 mm/year) as shown in Fig. (6).

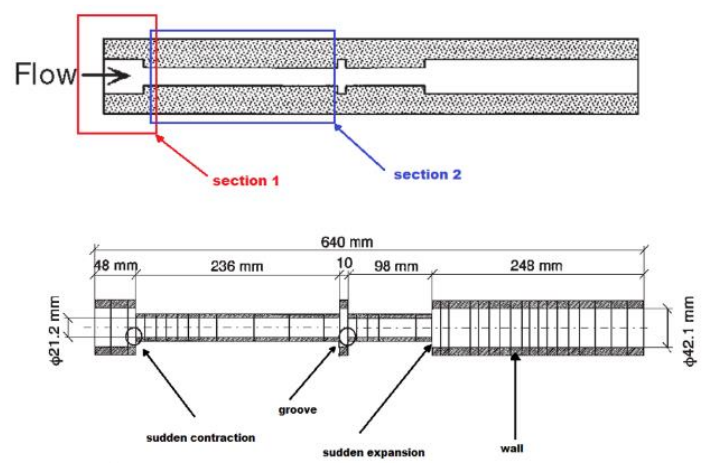

Fig. 5. The complex piping geometry for experimental study of Postlethwaite and Nesic [34]

Table 8. Experimental parameters and flow conditions

\begin{tabular}{cc}
\hline Carrier fluid & $\begin{array}{c}\text { Water, } 995.6\left(\mathrm{~kg} / \mathrm{m}^{3}\right) \text { density, 7.97 } \\
\times 10^{-4}(\text { pa.s }) \text { viscosity }\end{array}$ \\
\hline Pipe material & Stainless steel 304 (UNS S30400) \\
\hline Solid particles & Silica sand particles \\
\hline $\begin{array}{c}\text { Internal pipe } \\
\text { diameter }\end{array}$ & $\begin{array}{c}42.1(\mathrm{~mm}) \text { for large pipe, } 21.2 \\
(\mathrm{~mm}) \text { for small pipe }\end{array}$ \\
\hline Flow velocity & $\begin{array}{c}3.3(\mathrm{~m} / \mathrm{s}) \text { for large pipe, } 13.3(\mathrm{~m} / \mathrm{s}) \\
\text { for small pipe }\end{array}$ \\
\hline $\begin{array}{c}\text { Particles mass } \\
\text { flow rate }\end{array}$ & $0.294(\mathrm{~kg} / \mathrm{s})$ \\
\hline $\begin{array}{c}\text { Particle average } \\
\text { diameter }\end{array}$ & $430(\mu \mathrm{m})$ \\
\hline
\end{tabular}

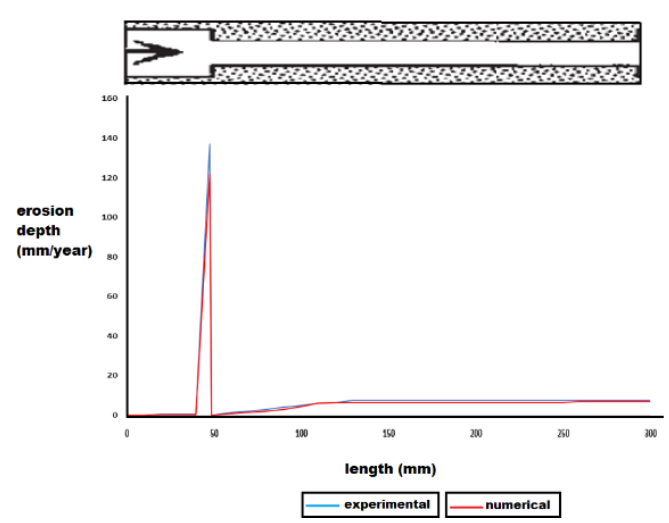

Fig. 6. Comparison of erosion depth profile between numerical results and experimental data of Postlethwaite and Nesic [34]

\section{RESULTS AND DISCUSSION}

\subsection{Straight pipe case}

The fluid velocity and streamlines distribution didn't change along the straight pipe because there is no changing in flow direction or cross section as shown in Fig. (7). The sand particles affected by the turbulence of flow and by the forces acting on, which leads to collide with wall and cause homogenous erosion along the pipe by $\left(8.72 \times 10^{-11} \mathrm{~kg} / \mathrm{m}^{2} . \mathrm{s}\right)$ as shown in Fig.(8). The effect of mass flow rate of sand particles, inlet flow velocity, particle diameter and internal pipe diameter on erosion has been illustrated in Table (9).

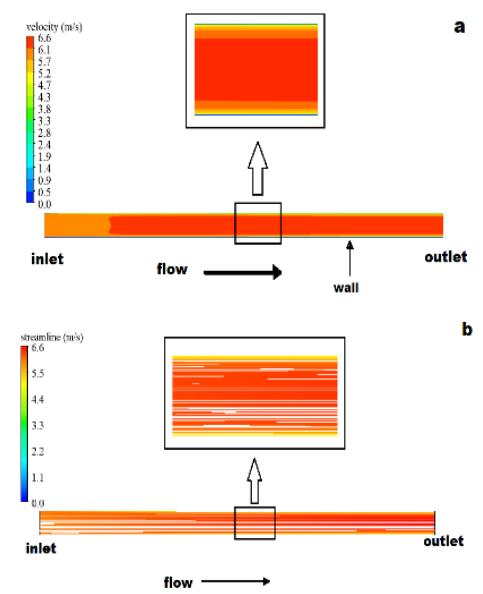

Fig. 7. Distribution of (a) velocity (b) streamlines

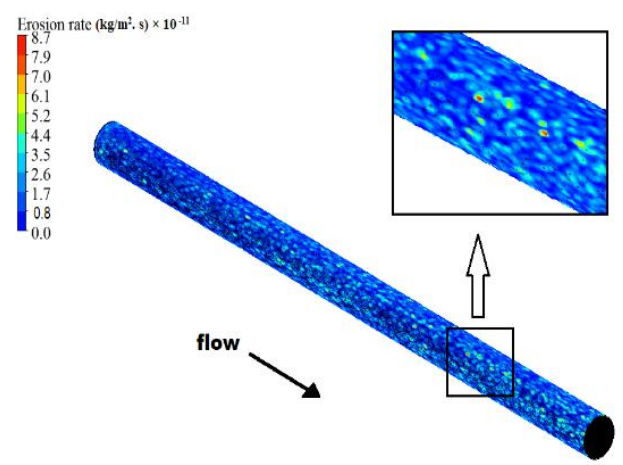

Fig. 8. Erosion behavior in straight pipe case

\subsubsection{Effect of mass flow rate of sand particles}

The erosion rate is increased with increasing mass flow rate of sand particles as given in Table (9). The investigated mass flow rates are: 0.001, 0.005, $0.01,0.05$ and $0.1 \mathrm{~kg} / \mathrm{s}$. The erosion rate is increased with mass flow rate, it was $\left(8.72 \times 10^{-11} \mathrm{~kg} / \mathrm{m}^{2} . \mathrm{s}\right)$ for $0.001 \mathrm{~kg} / \mathrm{s}$ and increased to $\left(9.83 \times 10^{-9} \mathrm{~kg} / \mathrm{m}^{2}\right.$.s $)$ i.e by $111.7 \%$ when mass flow rate increased to $0.1 \mathrm{~kg} / \mathrm{s}$ as given in Table (9). This increase of erosion rate is reported since more particles collide with pipe wall material leads to more erosion. Fig. (9-a) showed the relationship between mass flow rate and erosion rate in straight pipe. 
Table 9. The effects of different parameters on erosion rate in straight pipe case I

\begin{tabular}{|c|c|c|c|c|}
\hline $\begin{array}{c}\text { Mass } \\
\text { flow } \\
\text { rate of } \\
\text { particle } \\
(\mathrm{kg} / \mathrm{s})\end{array}$ & $\begin{array}{c}\text { Inlet } \\
\text { velocity } \\
\text { of fluid } \\
(\mathrm{m} / \mathrm{s})\end{array}$ & $\begin{array}{c}\text { Particle } \\
\text { diameter } \\
(\mu \mathrm{m})\end{array}$ & $\begin{array}{l}\text { Internal } \\
\text { pipe } \\
\text { diameter } \\
(\mathrm{mm})\end{array}$ & $\begin{array}{c}\text { Erosion rate } \\
\mathrm{kg} / \mathrm{m}^{2} \mathrm{~s}\end{array}$ \\
\hline 0.001 & 6 & 400 & 406.4 & $8.72 \times 10^{-11}$ \\
\hline 0.005 & 6 & 400 & 406.4 & $4.67 \times 10^{-10}$ \\
\hline 0.01 & 6 & 400 & 406.4 & $1.53 \times 10^{-9}$ \\
\hline 0.05 & 6 & 400 & 406.4 & $7.05 \times 10^{-9}$ \\
\hline 0.1 & 6 & 400 & 406.4 & $9.83 \times 10^{-9}$ \\
\hline 0.001 & 7 & 400 & 406.4 & $1.19 \times 10^{-10}$ \\
\hline 0.001 & 8 & 400 & 406.4 & $1.79 \times 10^{-10}$ \\
\hline 0.001 & 9 & 400 & 406.4 & $1.98 \times 10^{-10}$ \\
\hline 0.001 & 10 & 400 & 406.4 & $2.70 \times 10^{-10}$ \\
\hline 0.001 & 6 & 450 & 406.4 & $9.50 \times 10^{-11}$ \\
\hline 0.001 & 6 & 500 & 406.4 & $1.03 \times 10^{-10}$ \\
\hline 0.001 & 6 & 550 & 406.4 & $3.67 \times 10^{-10}$ \\
\hline 0.001 & 6 & 600 & 406.4 & $5.12 \times 10^{-10}$ \\
\hline 0.001 & 6 & 400 & 350 & $1.13 \times 10^{-10}$ \\
\hline 0.001 & 6 & 400 & 300 & $1.41 \times 10^{-10}$ \\
\hline 0.001 & 6 & 400 & 250 & $2.53 \times 10^{-10}$ \\
\hline 0.001 & 6 & 400 & 203.2 & $3.27 \times 10^{-10}$ \\
\hline
\end{tabular}

\subsubsection{Effect of inlet flow velocity}

In this work five fluid inlet velocities are investigated: 6, 7, 8, 9 and $10 \mathrm{~m} / \mathrm{s}$. Fig. (9-b) shows that erosion rate is increased with increasing flow velocity as given in Table (9). It was $\left(8.72 \times 10^{-11}\right.$ $\mathrm{kg} / \mathrm{m}^{2} . \mathrm{s}$ ) at $6 \mathrm{~m} / \mathrm{s}$ inlet velocity, then increased by $36.5 \%$ when inlet velocity increased by $16.7 \%$ i.e $\left(1.19 \times 10^{-10} \mathrm{~kg} / \mathrm{m}^{2} . \mathrm{s}\right)$. The erosion rate increase reaches $210 \%$ at $10 \mathrm{~m} / \mathrm{s}$ inlet velocity. The erosion rate rising occurs due to the increase in particle speed i.e increase of particle momentum leading to increase impaction energy and more erosion in pipe wall material.

\subsubsection{Effect of particle diameter}

The erosion rate in straight pipe is increased as particle diameter increased as illustrated in Fig. (9-c) and given in table (9). Five particle diameters have been examined: 400, 450, 500, 550 and $600 \mu \mathrm{m}$. It is reported that the erosion rate was $\left(9.5 \times 10^{-11} \mathrm{~kg} / \mathrm{m}^{2} . \mathrm{s}\right.$ at $450 \mu \mathrm{m})$. The erosion rate is increased by $8.4 \%$ when particle diameter increased from $450 \mu \mathrm{m}$ to $500 \mu \mathrm{m}$ (i.e for $12 \%$ increase in particle diameter). The erosion rate is continued in increasing rapidly with particle diameter, it reaches to $439 \%$ when the particle diameter be $600 \mu \mathrm{m}$. This increase in the erosion rate is due to more particle momentum affected on pipe wall is presented since larger particles have more mass then higher momentum energy compared with that for small particles.

\subsubsection{Effect of internal pipe diameter}

The erosion rate increased with decreasing the pipe internal diameter ID as shown in Fig. (9-d) and given in Table (9). The investigated pipe internal diameter ID are: 203.2, 250, 300, 350 and $406.4 \mathrm{~mm}$. The erosion rate is increased by $28 \%$ when internal pipe diameter is decreased by $13.8 \%\left(1.12 \times 10^{-11}\right.$ $\mathrm{kg} / \mathrm{m}^{2}$.s at $350 \mathrm{~mm}$ ), and increased by $273 \%$ for $50 \%$ decreasing in ID $\left(3.26 \times 10^{-10} \mathrm{~kg} / \mathrm{m}^{2} . \mathrm{s}\right.$ at $\left.203.2 \mathrm{~mm}\right)$.
The resulted increasing in erosion rate is due to the increase in flow turbulence and the volume fraction of sand particles as the internal pipe diameter decreased. This leads to rise particle collision with pipe wall material and increase erosion.

\subsection{Pipe with sudden contraction}

Two-phase (water-sand) flow in a horizontal pipe with sudden contraction (0.55 contraction ratio) shown in Figure (1-b) is simulated with the flow conditions given in Table (7). The distribution of
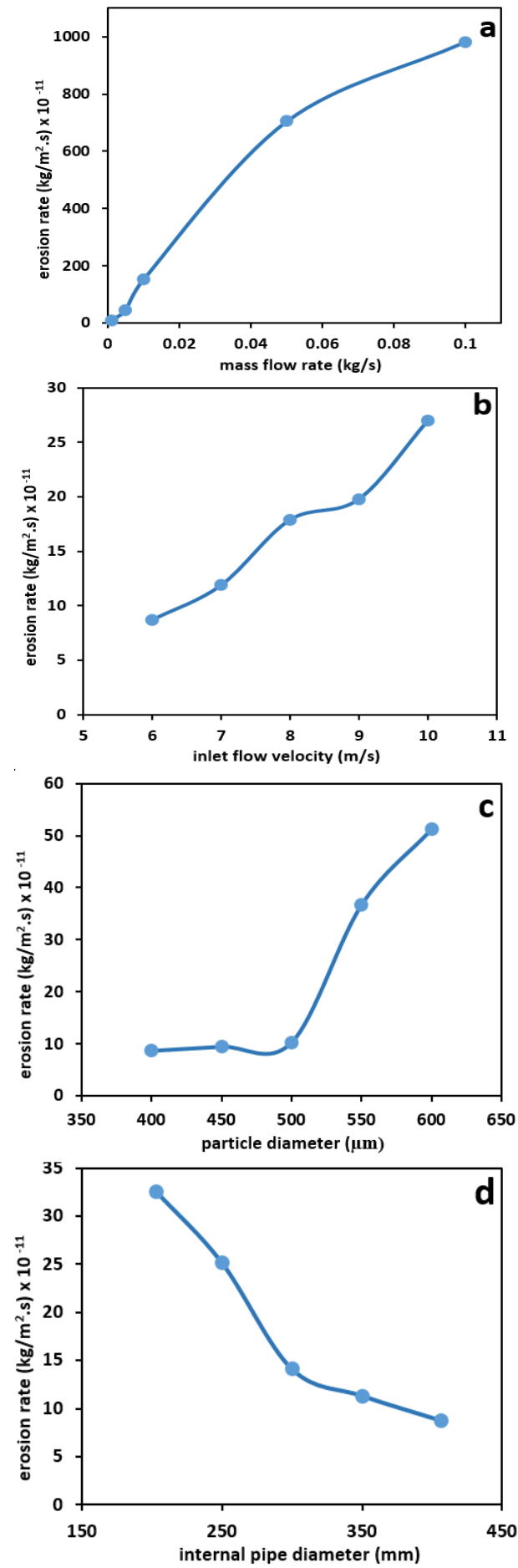

Fig. 9. The relationship between erosion rate and (a) mass flow rate of sand particles (b) inlet flow velocity (c) particle diameter (d) internal pipe diameter 
velocity and converging streamlines shown in Fig. (10) illustrates the increasing in flow velocity at the contraction section. The reported pressure reduction at contraction section shown in Fig. (11) is agreed with the expected behaviour according to Euler's equation along streamline. The maximum resulted erosion rate occurs at the step wall contraction area. It is of $\left(4.116 \times 10^{-8} \mathrm{~kg} / \mathrm{m}^{2} . \mathrm{s}\right)$ due to the direct impaction of sand particles with step wall area as shown in Fig.(12) since vortices region is formed before and after the contraction section.

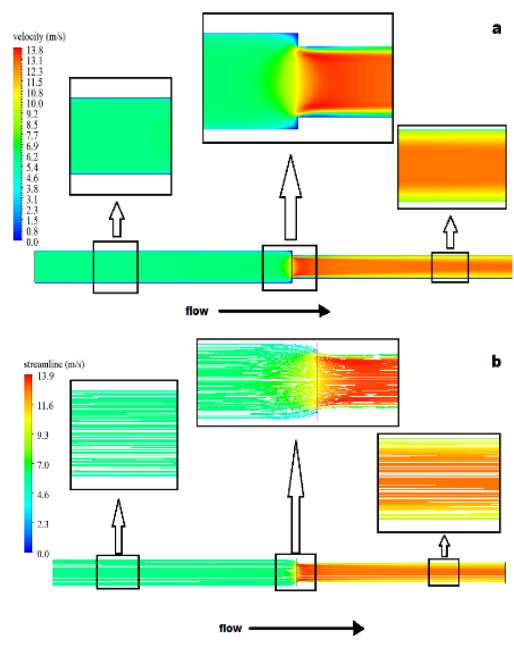

Fig. 10. Distribution of (a) flow velocity (b) streamlines

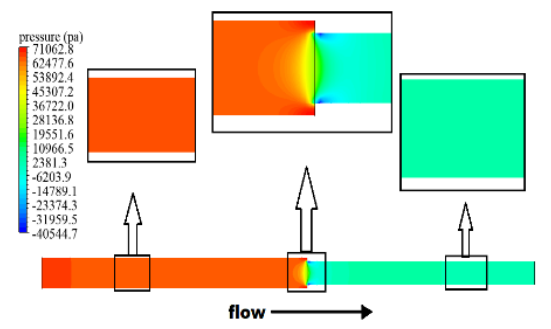

Fig. 11. Distribution of pressure

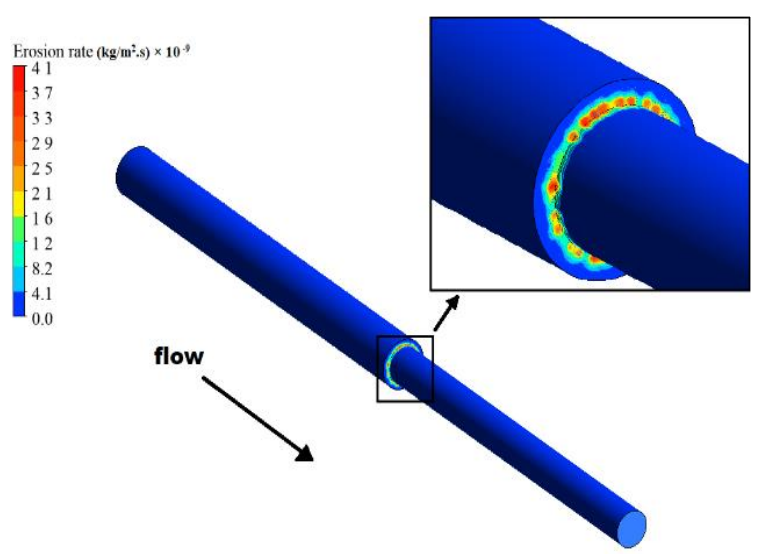

Fig. 12. Erosion behaviour in pipe with sudden contraction case

A parametric study is performed considering the effect of: mass flow rate of sand particles, inlet flow velocity, particle diameter, internal pipe diameter, contraction coefficient, step wall angle and orientation on erosion behavior as given in Table (10).

\subsubsection{Effect of mass flow rate of sand particles}

In this work it is found the erosion rate is increased with increasing mass flow rate of sand particles as presented in Fig.(13-a). It was (4.116 × $\left.10^{-8} \mathrm{~kg} / \mathrm{m}^{2} . \mathrm{s}\right)$ at $(0.001 \mathrm{~kg} / \mathrm{s})$ and increased by 99 times when mass flow rate is $0.1 \mathrm{~kg} / \mathrm{s}$ as given in Table (10). This is attributed to the increase in particles collisions with step wall material.

\subsubsection{Effect of inlet velocity}

The erosion rate is increased with increasing inlet flow velocity as shown in Fig. (13-b). It was (4.11 $\times$ $\left.10^{-8} \mathrm{~kg} / \mathrm{m}^{2} . \mathrm{s}\right)$ at $6 \mathrm{~m} / \mathrm{s}$ inlet velocity, then increased to $\left(7.33 \times 10^{-8} \mathrm{~kg} / \mathrm{m}^{2} . \mathrm{s}\right)$ at $7 \mathrm{~m} / \mathrm{s}$. Then increased to $\left(1.95 \times 10^{-7} \mathrm{~kg} / \mathrm{m}^{2} . \mathrm{s}\right)$ at $10 \mathrm{~m} / \mathrm{s}$. The momentum impact of the particles rises with the increase of particle speed, leading to increase the impact energy and more erosion in step wall material resulted.

\subsubsection{The effect of particle size}

The erosion rate in pipe with sudden contraction is increased as particle diameter increased till it reaches $500 \mu \mathrm{m}$ then it starts to decrease as presented in Fig.(13-c). At $550 \mu \mathrm{m}$, the erosion rate is increased again. It is found that for the working conditions illustrated in Table (8), the particle diameter of $500 \mu \mathrm{m}$ is form the critical diameter for the erosion in the pipe with sudden contraction. This behaviour is complicated since the flow in pipe contraction is associated with vena contracta phenomena synchronized with solid-liquid flow that results an interaction in the dominated forces for the particles with different diameters with pipe wall [32].

\subsubsection{Effect of pipe diameter}

Figure (13-d) illustrates an increase in the erosion rate with decreasing internal pipe diameter. It is increased by $70.8 \%$ when internal pipe diameter is reduced by $16.7 \%$ for the same contraction ratio of (0.5449). Erosion rate increasing continuously until it reaches $4.117 \times 10^{-7}$ for $66.7 \%$ reduction in pipe diameters. The erosion rate increasing occurs due to the increase in flow turbulence as pipe internal diameter decreased. This leads to rise of particle collision with pipe wall material.

\subsubsection{Effect of contraction ratio}

The contraction coefficient is an important factor influences the solid particle erosion in the pipe with sudden contraction. The obtained erosion rate is decreased rapidly with the increasing of contraction coefficient as illustrated in Fig. (13-e). The maximum decrease in erosion rate is found to be as $\left(498.66 \mathrm{~kg} / \mathrm{m}^{2} . \mathrm{s}\right)$ when contraction coefficient is increased from 0.0605 to 0.3784 for the same operating conditions given in Table (8). Also the 
decrease in erosion rate is predicted to be $(35.76$ $\left.\mathrm{kg} / \mathrm{m}^{2} . \mathrm{s}\right)$ as contraction coefficient increased from 0.13623 to 0.3784 . The increase in erosion rate resulted from the increase in step wall area so more sand particles collide with it and erosion rate increased.

\subsubsection{Effect of step wall angle}

The erosion rate is decreased when step wall angle is reduced as seen in Table (10). It is mean that the step wall is contracted gradually instead of suddenly as shown in Fig. (14). Erosion rate decreased by more than 30 times when the contraction wall angle is reduced to $30^{\circ}\left(1.24 \times 10^{-9}\right.$ $\mathrm{kg} / \mathrm{m}^{2}$.s at $30^{\circ}$ step wall angle). This could be considered as a pointed geometrical solution to reduce erosion in the pipe with contraction. The erosion reduction could be explained with that the particles are collide the step wall area tangentially instead of normally. The particles will lose part of their energy due impaction, leading to reduce erosion. The relation between step wall angle and erosion rate is illustrated in Fig. (13-f).

\subsubsection{Effect of orientation}

When the pipe orientation is changed from horizontal to vertical, the erosion rate increased by $6.1 \%$ as given in Table (10) (test No. 1 is considered as the reference). This increase is due to the effect of gravity, which made the particles accelerate in the direction of the flow, so these particles be abrasive due to their higher momentum effect, and resulted more eroded flow.
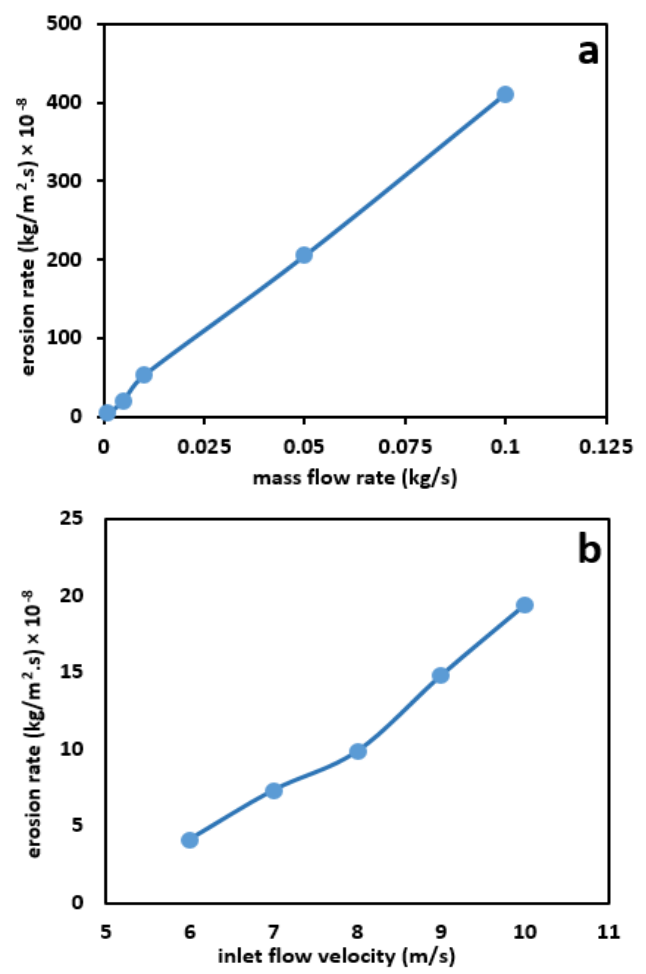
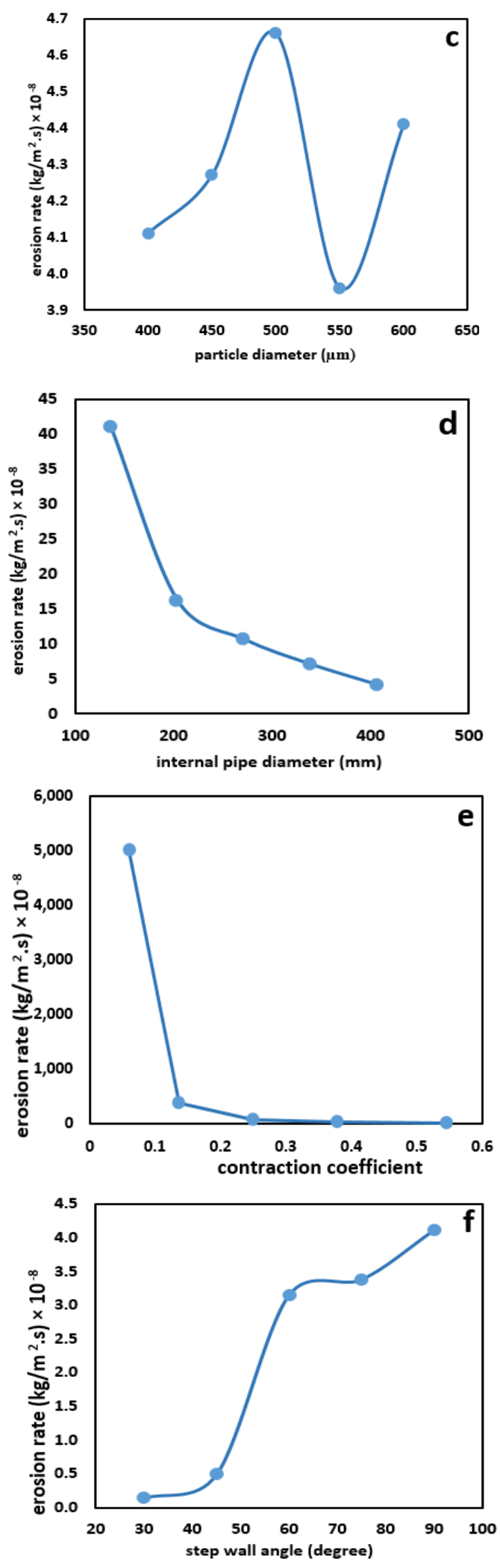

Fig. 13. Variation of erosion rate with: a) mass flow rate of sand particles, b) inlet flow velocity, c) sand particle diameter, d) internal pipe diameter, e) contraction coefficient, f) step wall angle 
Fig.14. Gradual contraction

Table 10. Effect of different parameters on erosion rate in pipe with sudden contraction case II

\begin{tabular}{|c|c|c|c|c|c|c|c|c|}
\hline No. & $\begin{array}{l}\text { Mass } \\
\text { flow } \\
\text { rate } \\
(\mathrm{kg} / \mathrm{s})\end{array}$ & $\begin{array}{c}\text { Inlet } \\
\text { velocity } \\
(\mathrm{m} / \mathrm{sec})\end{array}$ & $\begin{array}{c}\text { Particle } \\
\text { diameter } \\
(\mu \mathrm{m})\end{array}$ & $\begin{array}{l}\text { Internal pipe } \\
\text { diameter } \\
(\mathrm{mm})\end{array}$ & $\begin{array}{l}\text { Contraction } \\
\text { coefficient }\end{array}$ & $\begin{array}{l}\text { Step } \\
\text { wall } \\
\text { angle } \\
\text { (deg.) }\end{array}$ & Orientation & $\begin{array}{l}\text { Erosion rate } \\
\left(\mathrm{kg} / \mathrm{m}^{2} . \mathrm{s}\right)\end{array}$ \\
\hline 1 & 0.001 & 6 & 400 & 406.4 - 300 & 0.5449 & $90^{\circ}$ & horizontal & $4.12 \times 10^{-8}$ \\
\hline 2 & 0.005 & 6 & 400 & $406.4-300$ & 0.5449 & $90^{\circ}$ & horizontal & $2.06 \times 10^{-7}$ \\
\hline 3 & 0.01 & 6 & 400 & $406.4-300$ & 0.5449 & $90^{\circ}$ & horizontal & $5.285 \times 10^{-7}$ \\
\hline 4 & 0.05 & 6 & 400 & $406.4-300$ & 0.5449 & $90^{\circ}$ & horizontal & $2.06 \times 10^{-6}$ \\
\hline 5 & 0.1 & 6 & 400 & $406.4-300$ & 0.5449 & $90^{\circ}$ & horizontal & $4.12 \times 10^{-6}$ \\
\hline 6 & 0.001 & 7 & 400 & $406.4-300$ & 0.5449 & $90^{\circ}$ & horizontal & $7.33 \times 10^{-8}$ \\
\hline 7 & 0.001 & 8 & 400 & $406.4-300$ & 0.5449 & $90^{\circ}$ & horizontal & $9.87 \times 10^{-8}$ \\
\hline 8 & 0.001 & 9 & 400 & $406.4-300$ & 0.5449 & $90^{\circ}$ & horizontal & $1.48 \times 10^{-7}$ \\
\hline 9 & 0.001 & 10 & 400 & $406.4-300$ & 0.5449 & $90^{\circ}$ & horizontal & $1.95 \times 10^{-7}$ \\
\hline 10 & 0.001 & 6 & 450 & $406.4-300$ & 0.5449 & $90^{\circ}$ & horizontal & $4.28 \times 10^{-8}$ \\
\hline 11 & 0.001 & 6 & 500 & $406.4-300$ & 0.5449 & $90^{\circ}$ & horizontal & $4.66 \times 10^{-8}$ \\
\hline 12 & 0.001 & 6 & 550 & $406.4-300$ & 0.5449 & $90^{\circ}$ & horizontal & $3.96 \times 10^{-8}$ \\
\hline 13 & 0.001 & 6 & 600 & $406.4-300$ & 0.5449 & $90^{\circ}$ & horizontal & $4.41 \times 10^{-8}$ \\
\hline 14 & 0.001 & 6 & 400 & $338.66-250$ & 0.5449 & $90^{\circ}$ & horizontal & $7.03 \times 10^{-8}$ \\
\hline 15 & 0.001 & 6 & 400 & $271-200$ & 0.5449 & $90^{\circ}$ & horizontal & $1.06 \times 10^{-7}$ \\
\hline 16 & 0.001 & 6 & 400 & $203.2-150$ & 0.5449 & $90^{\circ}$ & horizontal & $1.63 \times 10^{-7}$ \\
\hline 17 & 0.001 & 6 & 400 & $135.46-100$ & 0.5449 & $90^{\circ}$ & horizontal & $4.12 \times 10^{-7}$ \\
\hline 18 & 0.001 & 6 & 400 & $406.4-250$ & 0.3784 & $90^{\circ}$ & horizontal & $2.34 \times 10^{-7}$ \\
\hline 19 & 0.001 & 6 & 400 & $406.4-203.2$ & 0.25 & $90^{\circ}$ & horizontal & $6.38 \times 10^{-7}$ \\
\hline 20 & 0.001 & 6 & 400 & $406.4-150$ & 0.13623 & $90^{\circ}$ & horizontal & $3.81 \times 10^{-6}$ \\
\hline 21 & 0.001 & 6 & 400 & $406.4-100$ & 0.0605 & $90^{\circ}$ & horizontal & $5.01 \times 10^{-5}$ \\
\hline 22 & 0.001 & 6 & 400 & $406.4-300$ & 0.5449 & $75^{\circ}$ & horizontal & $3.38 \times 10^{-8}$ \\
\hline 23 & 0.001 & 6 & 400 & $406.4-300$ & 0.5449 & $60^{\circ}$ & horizontal & $3.15 \times 10^{-8}$ \\
\hline 24 & 0.001 & 6 & 400 & $406.4-300$ & 0.5449 & $45^{\circ}$ & horizontal & $4.94 \times 10^{-9}$ \\
\hline 25 & 0.001 & 6 & 400 & $406.4-300$ & 0.5449 & $30^{\circ}$ & horizontal & $1.42 \times 10^{-9}$ \\
\hline 26 & 0.001 & 6 & 400 & $406.4-300$ & 0.5449 & $90^{\circ}$ & vertical & $4.37 \times 10^{-8}$ \\
\hline
\end{tabular}

\section{CONCLUSIONS}

According to the two-way coupled with Eulerian-Lagrangian approach and the coupled erosion model with constant coefficient of restitution. A 3-D numerical analysis was proposed to investigate the erosion of two phase (sand-water) turbulent flow in two piping geometries: straight pipe and pipe with sudden contraction. The effect of solid particle mass flow rate, inlet velocity, pipe diameter, particle size, contraction ratio, step wall angle and orientation are examined. The conclusions could be drawn are:

(1) The erosion behavior distributed homogenously in the straight pipe case. But, in the pipe with 
sudden contraction the most erosive area is at the step wall.

(2) The erosion rate increased with increasing solid particles concentration, increasing inlet velocity and decreasing pipe diameter for both straight pipe, and pipe with contraction section.

(3) The erosion behavior is not conserved with the effect of particle size in the present considered pipe geometries. For the straight pipe, the erosion rate increased with increasing particle size. While, for pipe with sudden contraction, the erosion rate increased with increasing particle size till particle critical diameter of $500 \mu \mathrm{m}$. Then erosion rate is decreased, and start to increase again after $550 \mu \mathrm{m}$ particle diameter.

(4) Increasing the contraction ratio of the pipe with sudden contraction decreases the erosion rate.

(5) The erosion rate in the pipe with a contraction is highly influenced by the angle of step wall. The erosion rate decreased by 30 times with decreasing step wall angle to $30^{\circ}$ compared with that for $90^{\circ}$. So, changing the step wall angle could be considered as geometrical solution to reduce erosion rate in the pipe with contraction.

Author contributions: research concept and design, K.E.A.; Collection and/or assembly of data, Z.Al-S.; Data analysis and interpretation, Z.Al-S; Writing the article, K.E.A., Z.Al-Z.; Critical revision of the article, K.E.A.; Final approval of the article, Z.Al-S.

Declaration of competing interest: The authors declare that they have no known competing financial interests or personal relationships that could have appeared to influence the work reported in this paper.

\section{REFERENCES}

1. Abdulla A. Estimating erosion in oil and gas pipeline due to sand presence 2016. MSc thesis, Department of mechanical engineering, Blekinge Institute of Technology, Karlskrona, Sweden. urn:nbn:se:bth$\underline{6209}$

2. Al-Baghdadi MA, Resan KK, Al-Waily M. CFD investigation on the erosion severity in 3D flow elbow during crude oil contaminated sand transportation. Engineering and Technology 2017; 35 (9): 930-935.

3. Al-Khayat RH, Al-Baghdadi MARS, Neama RA, AlWaily M. Optimization CFD study of erosion in 3D elbow during transportation of crude oil contaminated with sand particles. Engineering and Technology 2018; 7(3): 1420-1428. http://dx.doi.org/10.14419/ijet.v7i3.14180

4. ANSYS-FLUENT Theory Guide 15.0, Ansys, Inc, (2013).

Ataiwi AH, Ayad KH, Ban AF, Al-Saadi. Erosion behavior of steel pipes carrying of some Iraqi crude oils; Engineering and Technology 2016; 34 (1) Part A: 85-95.

5. Clark. H. Mci. Particle velocity and size effects in laboratory slurry erosion measurements or ... do you know what your particles are doing?. Tribology International 2002; 35 (10): 617-624. https://doi.org/10.1016/S0301-679X(02)00052-X
6. Faeth GM. Spray atomization and combustion. Technical Report AIAA 1986; 86-0136: 1-17. https://doi.org/10.2514/6.1986-136

7. Finnie I. Erosion of surfaces by solid particles. Wear 1960; 3 (2): 87-103.

https://doi.org/10.1016/0043-1648(60)90055-7

8. Finnie I. The mechanism of erosion of ductile metals. Proceedings of the third national congress on applied mechanics. 1958; New York 527- 532.

9. Gosman AD, Ioannides E. Aspects of computer simulation of liquid-fueled combustors. Journal of Energy 1983; 7 (6): 482-490. https://doi.org/10.2514/3.62687

10. Hutching I, Winter R. Particle erosion of ductile materials: a mechanism of material removal. Wear 1974; 27 (1):121-128. https://doi.org/10.1016/0043-1648(74)90091-X

11. Jafri M, Mansoori Z, Saffar Avval M, Ahmadi G. The effects of wall roughness on erosion rate in gas-solid turbulent annular pipe flow. Powder Technology 2015; 271: pp. 284-245. https://doi.org/10.1016/j.powtec.2014.11.024

12. Jha AK, Batham R, Ahmed M, Majumder AK, Modi OP, Chaturvedi S, Gupta AK. Effect of impinging angle and rotating speed on erosion behavior of aluminum. Transactions of Nonferrous Metals Society of China 2011; 21 (1): 32-38. https://doi.org/10.1016/S1003-6326(11)60674-2

13. Johar ZM, Jadid, MSA. Zamberi, SNA. Shaffee CY. Wong, CB, Solnordal J. Boulanger. Experimental and CFD erosion modelling of large radius pipe elbows liquid. International Petroleum Technology Conference 2014. https://doi.org/10.2523/IPTC-17926-MS

14. Jordan KG. Erosion in multiphase production of oil \& gas. NACE international 1998, San Diego, California.

15. Kang R, Haixiao L. An integrated model of predicting sand erosion in elbows for multiphase flows. Powder Technology 2020; 366: 508-519. https://doi.org/10.1016/j.powtec.2020.02.072

16. Kosinska A, Balakin BV, Kosinski P. Theoretical analysis of erosion in elbows due to flows with nano and micro size particles, Powder Technology 2020; 364: 484-493. https://doi.org/10.1016/j.powtec.2020.02.002

17. Levy AV. Solid particle erosion and erosion-corrosion of materials, ASM International 1995. Material Park. Ohio.

18. Mackey ED, Thomas FS. Guidelines for using stainless steel in the water and desalination industries, Journal Awwa 2017; 109 (5): 158-169. https://doi.org/10.5942/jawwa.2017.109.0044

19. Mansouri A. A combined CFD - experimental method for developing an erosion equation for both gas - sand and liquid - sand flow. Ph.D thesis. The University of Tulsa 2016, OK, USA.

20. Mazumdar Q, Nallamothu VT, Mazumder F. Comparison of characteristic particle velocities in solid-liquid multiphase flow in elbow. International Journal of Thermofluids 2020; 5-6. https://doi.org/10.1016/j.ijft.2020.100032

21. Mazumder. QH. CFD analysis of the effect of elbow radius on pressure drop in multiphase flow. Hindawi Publishing Corporation 2012. https://doi.org/10.1155/2012/125405

22. Mazumder. QH. Effect of liquid and gas velocities on magnitude and location of maximum erosion in U- 
bend, Open Journal of Fluid Dynamics 2012; 2: pp. 2934. http://dx.doi.org/10.4236/ojfd.2012.22003

23. Meng HC, Ludema KC. Wear modela and predictive equations -their form and content. Wear 1995; 181183 part 2: 443-457. https://doi.org/10.1016/0043-1648(95)90158-2

24. Morsi SA, Alexander AJ. An investigation of particle trajectories in two-phase flow system, Journal of Fluid Mechanics 1972; 55 (2): 193-208. https://doi.org/10.1017/S0022112072001806

25. Neilson JH, Gilchrist A. Erosion by steam of solid particles, Wear 1968; 11 (2): 111-122. https://doi.org/10.1016/0043-1648(68)90591-7

26. Oka YI, Okamura K, Yoshida T. Practical estimation of erosion damage caused by solid particle impact: Part1: Effects of impact parameters on a predictive equation, Wear 2005; 259 (1-6): 95-101. https://doi.org/10.1016/j.wear.2005.01.039

27. Oka YI, Yoshida T. Practical estimation of erosion damage caused by solid particle impact: Part2: Mechanical properties of materials directly associated with erosion damage, Wear 2005, 259 (1-6): 102-109. https://doi.org/10.1016/j.wear.2005.01.040

28. Parsi M, Najmi K, Najafifard F, Hassani S, Mclaury BS, Shirazi SA. A comprehensive review of solid particle erosion modeling for oil and gas wells and pipelines applications, Journal of Natural Gas Science and Engineering 2014; 21: 850-873.

https://doi.org/10.1016/j.jngse.2014.10.001

29. Parsi. M, Netaji RK, Siamack AS, Brenton S. Effects of flow pattern and flow orientation on sand erosion in elbows for multiphase flow conditions, NACE International 2015.

30. Patil MS, Eknath RD, Ramchandra SJ, Santosh VP. Study of the parameters affecting Erosion wear of ductile Material in solid-liquid mixture, Proceedings of the World Congress on Engineering 2011; 3.

31. Peng W, Cao. X. Numerical simulation of solid particle erosion in pipe bends with liquid-solid flow. Powder Technology 2016; 294 :266-279. https://doi.org/10.1016/j.powtec.2016.02.030

32. Peng W, Cao X, Xu K, Fan Y, Xing S. Experiment and numerical simulation of sand particle erosion under slug flow condition in a horizontal pipe bend. Journal of Natural Gas Science and Engineering2020; 76. https://doi.org/10.1016/j.jngse.2020.103175

33. Postlethwaite J, Nesic S. Erosion in disturbed liquid/particle pipe flow: Effects of flow geometry and particle surface roughness. Corrosion 1993; 49 (10): 850-857.

34. Raghavendra HN, Shivashankar M, Prem AR. Simulation of erosion wear in choke valves using CFD. International Journal of Engineering Research \& Technology 2014; 3 (7).

Simulation of Erosion Wear in Choke Valves using CFD (ijert.org)

35. Sandeep CS, Senetakis K, Cheung D, Choi CE, Wang Y, Coop MR, Ng CW. Experimental study on the coefficient of restitution of grain against block interfaces for natural and engineered materials, Canadian Geotechnical Journal 2021; 58 (1). https://doi.org/10.1139/cgj-2018-0712

36. Shaheed R, Mohammadian A, Gildeh HK. A comparison of standard $\mathrm{k}-\varepsilon$ and realizable $\mathrm{k}-\varepsilon$ turbulence model in curved and confluent channels, Environmental Fluid Mechanics 2019; 19: 543-568. https://link.springer.com/article/10.1007/s10652-018$\underline{9637-1}$
37. Shamshirband. S, Amir M, Arash K, Marjan G, Masoud A, Dalibor P, Mahidzal D, Naghmeh M. Performance investigation of micro and nano sized particle erosion in a $90^{\circ}$ elbow using an ANFIS model. Powder Technology 2015; 284: 336-343. https://doi.org/10.1016/j.powtec.2015.06.073

38. Tebowei R. Computational Fluid Dynamics (CFD) modelling for critical velocity for sand transport flow regimes in multiphase pipe bends. $\mathrm{PhD}$ thesis 2016, Robert Gordon University, United Kingdome. http://hdl.handle.net/10059/2118

39. Veritas DV. Recommended particle, Erosion wear of piping system. DNV RPO. 501. 2007.

40. Vieira R, Parsi M, Zahedic P, McLauryc BS, Shirazi SA. Electrical resistance probe measurements of solid particle erosion in multiphase annular flow. Wear 2017; 382-383: pp. 15-28. https://doi.org/10.1016/j.wear.2017.04.005

41. Wang. K, Xiufeng L, Yueshe W, Renyang H. Numerical investigation of erosion behavior in elbows of petroleum pipelines. Powder Technology 2017; 314: 490-499. https://doi.org/10.1016/j.powtec.2016.12.083

42. Yousif IF, Ali HA. Construction of slurry jet erosion tester and effect of particle size on slurry erosion. Kufa Journal of Engineering 2017; 9 (3): 17-25. http://dx.doi.org/10.30572/2018/kje/090302

43. Zhang G, Yi FZ, Qi L, Yi L, Zhe L. Experimental study on the two-phase flow of gas-particles through a model brake valve, Power Technology 2020; 367: 172-182.

https://doi.org/10.1016/j.powtec.2020.03.047

44. https://material-properties.org/density-of-materials/

Received 2022-01-02

Accepted 2022-03-07

Available online 2022-03-08

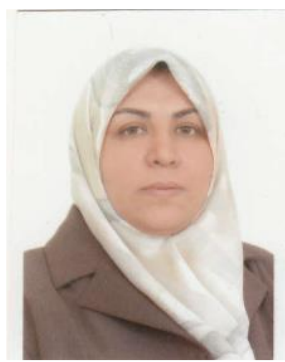

Karima E. AMORI was born in Baghdad, Iraq in 1963. She received the B.Sc. degree in Mechanical engineering from the University of Baghdad, in 1985, M.Sc. in Mechanical Engineering in 1990 from the University of Baghdad, and the Ph.D. degree in Mechanical engineering in 2005. She was professor in Thermo-Fluid from 23/2/2013 till now at the University of Baghdad, college of Engineering, Mechanical Engineering Department.

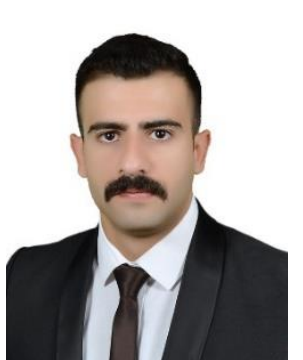

Zaid Al. SALMANY was born in Baghdad, Iraq in 1992. he received the Bachelor's degree in mechanical engineering from Arabian Gulf Academy for Maritime Studies - Navy college in 2015. Currently M.Sc. student in University of BaghdadMechanical engineering department researching in the field of particle erosion in raw water pipe fittings for multiphase flow. 